\title{
Occupational Health and Safety Conditions from 2010 to 2018 in Different Major Industrial Sectors of Pakistan
}

\author{
Satesh Kumar Devrajani, Uzma Imran
}

\begin{abstract}
Globalization can be identified in worldwide as industrialization. While economic globalization has brought economic growth and new prosperity to many regions of the world, it has also brought with it a growing safety problem. While there are many risks to health and safety in the workplace, there is a chance for the global community as well. The present study examines the numbers of working persons injured in different major sectors covered by the 2010-2018 Pakistan Labor Force Surveys. The paper also aims to identify the causes for incidents in different industries in order to make suggestions for improving health and safety conditions in Pakistan.
\end{abstract}

Keywords: Occupational health, safety, injuries and accidents, industrial sectors, Pakistan.

\section{INTRODUCTION}

Since the Industrial Revolution, rapid technological development has led to the transformation of human lives; moreover, the same growth has resulted in an increased risk to human beings' protection and health. Not only for employees, but also for the employer itself, workplace injuries or work accidents are considered a concern. These injuries, in addition to jeopardizing the lives and well-being of employees, cause a rise in absences in the workplace and a decline in labour productivity, resulting in an increased burden for companies [1]. The International Labor Organization (ILO) has calculated that the economic costs of these workplace accidents and diseases are on average 1\%-3\% in developed countries and 4\% of GDP in developing countries [2]. According to the ILO, about 2.3 million deaths and 300 million injuries occur in workplaces worldwide each year, and even then, these figures do not accurately reflect the severity of the problem [3]. In the developing countries, the adequate trainings are having not been provided to the labour and staff, or health care facilities are not advanced and lack of other facilities. Safety standards may vary from country to country and sector to sector. In less developed countries, for example, industry divisions like construction \& agriculture account for a higher percentage of overall occupational injuries/diseases since a significant proportion of the workforce is working in this field and high-risk work are part of those jobs [4].

Pakistan has the world's 9th largest labour force, according to the Pakistan Economic Survey 2019-20, and nearly $66 \%$ of the labour force is directly or indirectly linked with construction \& manufacturing, agriculture \& forestry, and fishing sectors [5]. However, agriculture is responsible for the highest percentage of occupational injuries/diseases, a huge number of fatalities are considered the most hazardous and dangerous accounting for the construction sector [6]. Many contractors hire several workers, who push them to finish the tasks on tight deadlines \& compromise on worker protection in the process. The Occupational Health \& Safety conditions in Pakistan, whether the enforcement of laws, the legislation, resource needed or the data collection, have needed an urgent revamp. Based on the changing developments in different manufacturing sectors that add to the complexities, the law has not been revised. The Factories Act 1934, for example, does not refer to businesses with less than 10 employees and, moreover, does not include the agricultural, seasonal \& informal industries. In addition, accidental insurance as well as other benefits such as death grants and disability pensions are covered by very limited numbers of workers in the sectors. Only 36 ILO Conventions have been ratified by the Government of Pakistan, of which 3 conventions have already been decried [9]. It is not possible to take appropriate action to target those sectors that need immediate and serious attention with such limited the limited data showing statistical trends.

In many industries of Pakistan of mining and quarrying, many accidents and fatalities have caused due to working conditions. Several diseases have resulted Tuberculosis due to inhale of toxic elements with the dust by workers even though they manage to survive [10]. On the other side, textile industries and other manufacturing sectors of Pakistan also been suffering the same situation. The waste pollution ejection is caused due to most of the industries and also have experienced fire accidents. In 
the industries, the number of accidents is added up due to without the understanding of the risks and a thorough training of the complex machinery [11]. Hence, it is so important to know the reasons behind the accidents, so that the occurrence of such risk can be reduced efficiently.

\section{Methodology}

There are many chances of accidents in every industry division, whether it is mining construction or manufacturing industry and in developing countries like Pakistan, these industries account for a higher number of accidents. In this study, from the Pakistan Bureau of Statistics, the previous data from 2010 to 2018 was obtained, which will be analyzed for different sectors. In addition, an attempt will be made in each of the sectors to clarify the reasons behind these injuries/diseases, and some recommendations will be given to strengthen the culture of health and safety in Pakistan.

This report includes data obtained from the Labor Force Surveys, which are available on the Pakistan Bureau of Statistics website and are regularly updated annually. The percentages of occupational injuries/diseases for the above industries were collected between 2010 and 2018 and the patterns were evaluated using 2010 as the base year.

\section{RESUlT AND DisCUSSION}

The information provided in Table 1 is part of a systematic analysis of OSH conditions in Pakistan, using the related statistical data from the Labor Force Surveys. This study provides details from the last five Labor Force Reports on workplace incidents and injuries (2010-11, 2012-13, 2013-14, 201415 and 2017-

$18)$.

Table1. Percentage Distribution of Employed Persons who suffered Occupational Injuries/Diseases by Major Industry Divisions (Pakistan Bureau of Statistics, Labor Force Surveys)

\begin{tabular}{|l|l|l|l|l|l|}
\hline Industry Divisions & $\mathbf{2 0 1 0 - 2 0 1 1}$ & $\mathbf{2 0 1 2 - 2 0 1 3}$ & $\mathbf{2 0 1 3 - 2 0 1 4}$ & $\mathbf{2 0 1 4 - 2 0 1 5}$ & $\mathbf{2 0 1 7 - 2 0 1 8}$ \\
\hline Agriculture/Forestry/Fis hing & 49.77 & 49.85 & 51.16 & 47.95 & 41.6 \\
\hline Manufacturing & 15.78 & 13.32 & 14.21 & 15.90 & 17.0 \\
\hline Construction & 13.10 & 15.24 & 14.14 & 16.27 & 17.3 \\
\hline Mining/Quarrying & 0.23 & 0.21 & 0.26 & 0.27 & 0.3 \\
\hline Others* & 21.12 & 22.08 & 20.23 & 19.61 & 25.7 \\
\hline
\end{tabular}

*Others include Community, Social and Personal Services/ Transport, Storage \& Communication /Wholesale \& Retail Trade, Restaurant \& Hotels/ Electricity, Gas \& Water/Other Industry Divisions.

In the table 1, is clearly shown that from 2010 to 2015 the agriculture/forestry/fishing sector is almost $50 \%$ of occupational injuries/diseases in Pakistan. But in 2017-18 the percentage declined upto 41.6 $\%$. The manufacturing and construction sectors contain around $30 \%$ of occupational injuries from 2010 to 2015 , but in 2017-18 this percentage inclined approximately by $4 \%$. In first four years the percentage is nearly same but there are fluctuations in the last year as compared to the other years.

\subsection{Agriculture/Fishing/Forestry Sector}

Large number of accidents in agriculture/fishing/forestry sector occur due to some major causes behind. This sector employs a great percentage of workers (42.34\% in 2017-18) is one of the major reasons and also has contributed to the GDP of $19.6 \%$ in 2017-18. The workers which are directly or indirectly involved in this sector, most of them are illiterate, females and children living in rural areas of Pakistan. Like other countries, there is no insurance or other disability benefits are considered for the workforce. Furthermore, health and safety of the workers can be endangered due to extreme weather conditions, health facilities and poor infrastructures. Large number of people living in rural areas, they cannot easily access education even high school graduation. About 80 to $85 \%$ of the population who had encountered occupational injuries/diseases had no higher education, showing a clear link between education and the prevention of occupational injuries/diseases. [6, 12, 13].

High number of injuries caused due to a common factor which is child labour. Illiterate people living in rural areas, they prefer their children to start working instead of sending them school. However, the children are not educated to trained to understand the dangers of the operating machineries and hand tools and therefore, they suffer from serious injuries. 
The other reasons that give rise to the number of occupational injuries/diseases are the extreme climatic conditions that workers are exposed to in the agriculture/forestry/fishing sector, those associated with agriculture and fisheries. Pakistan's diverse terrain and climate conditions make it susceptible to natural disasters ranging from severe floods to earthquakes [15]. Several rivers swell and flood the agricultural fields in the summer months, when the monsoon season prevails in Pakistan, destroying crops and cattle and sweeping away the people who live and work on farms. In spite of large investments in disaster control, floods have occurred consistently, resulting in the loss of dozens of lives and the displacement of 82,000 people in 2009 and 2008 [16]. Although the size of fertile land has lessened over the years due to floods, the percentage of occupational injuries/diseases during the 2010-2018 period has remained quite steady. Instead of disaster prevention, government policy is focused on relief work. Fishermen's populations live around contaminated seawater bears with bad sanitary conditions and sometimes catch rotten fish diseases [18].

\subsection{Manufacturing Sector}

Manufacturing in combination with the construction industry accounts for nearly $15 \%$ of total workplace injuries/diseases. It is important to understand the reasons why people work in the manufacturing sector have a high incidence of occupational injuries/diseases, taking into account the importance of employees as the real backbone of the industry. Crucial causes are inadequate working conditions and the lack of a successful screening policy for work injury. For example, musculoskeletal disorders in sugar industry faced by many workers due to heavy load raising, carrying, pushing and pulling in sugar mills. Another explanation is that most of the workers who were injured in sugar mills were untrained and not wearing suitable equipment such as helmets, gloves and uniforms [19, 20]. The textile industry, which is the main manufacturing sector, is another characteristic paradigm. The use of improper lighting in stitching units is not necessary and does not protect vision problems. The system of ventilation in these textile industries stitching units is not so good and illness and respiratory issues are prevalent among workers [21]. As a result of the production, use, storage, transport, handling and disposal of chemicals, massive occupational and environmental problems are faced. Also, heat stress is dangerous. Heat can also predetermine other requirements for workers. It is hard to wear protective equipment such as gloves, uniforms and consequently to be exposed to other risks in hot condition. Many manufacturing workers are not well prepared to face risks due to lack of basic infrastructures and qualified staff to provide occupational health and safety services $[22,23]$.

\subsection{Construction Sector}

Occupational health and safety issues are widespread in the construction industry. Even in modern societies, construction work has been found to be a high occupational risk [24, 25]. According to the Hong Kong Polytechnic University, the key reasons for this are: the high rise in houses, which remains prominent among others. Due to working at heights and with the vertical transport of materials such as the fall of a person or the fall of objects, many hazards occur. Secondly, most construction sites that do not have adequate storage spaces or spaces for ancillary work are crowded. Stepping on, striking against or being hit by objects are the most common injuries. Last but not least, people with labourintensive techniques are still working at construction sites [26]. Other important reasons, apart from the general reasons in force in most countries, especially in the Pakistani construction industry, are the insufficient security facilities given to workers and the innumeracy of workforce so as not to be aware of safety measurements [27]. It is evident that professions such as assemblers and machine and plant operators, associate professionals and technicians, and elementary occupations are covered by the construction industry. Figure 1, which applies to the period 2017-2018, indicates that approximately 50 percent of occupational diseases/injuries are covered by these practitioners. 


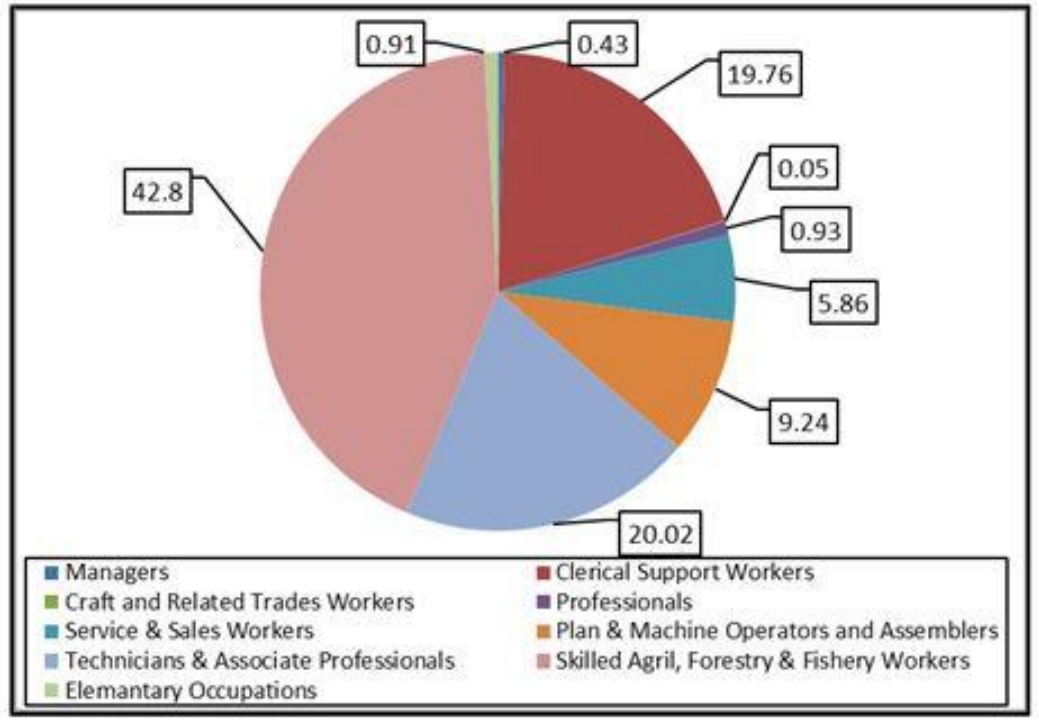

Figure1. Percentage of Occupational Diseases/Injuries by Occupation 2017-2018

Table 2, which indicates the level of education, is another supporting reason. Most occupations in the construction industry (with the exception of engineers) do not require a particular degree. It is obvious that persons which constitute the vast majority of people who work in construction industry.

Table2. Distributed of Employed Persons Suffered Occupational Diseases/Injuries by Literacy and Educational Level (\%) from 2017 to 2018

\begin{tabular}{|c|c|}
\hline Level of Education & $\mathbf{2 0 1 7 - 2 0 1 8}$ \\
\hline Illiterate & 37.7 \\
\hline Literate & 62.3 \\
\hline Below matric & 36.9 \\
\hline Matric but less than Intermediate & 11.9 \\
\hline Intermediate but less than Degree & 5.9 \\
\hline Degree and Above & 6.0 \\
\hline No formal education & 1.6 \\
\hline
\end{tabular}

\subsection{Mining and Quarrying Sector}

The mining and quarrying sector is high risk in nature and many well published investigations into major catastrophes such as Benxihu Colliery disaster in 1942 to China with 1,549 deaths, Couriers Coal Mine disaster in 1906 to France with 1,099 deaths, Mitsubishi Hojyo Coal Mine disaster in 1914 to Japan with 687 deaths, Dhanbad Coal Mine disasters in 1965 and in 1975 to India with 375 and 372 deaths equivalently have focused the attention of both operating and contracting company management on safety issues [28]. According to Rosen and James, hazardous conditions, unsafe actions, or both, are the fundamental causes of accidents and injuries in mines [29]. Sernia and Hwang, on the other hand, argue that disasters in the mining industry occur due to massive mine fires, strong mine explosions and violent detonations of rock gas [30]. Back injuries due to manual material handling accidents are significant accidents in the mining and quarrying industry. The risk of accidents is increased by limited, poorly maintained work areas and low visibility. Contrary to safety laws, most employees were found to work without gloves, safety boots and a suitable uniform with a hat [31]. Another significant reason for occupational injuries in Mining and Quarrying sector is the ground fall which takes place because of 1) geological anomalies presence of faults, slips, joints and clay vein, 2) weathering effect roof deterioration due to temperature changes and moisture and 3) stress conditionsconcentration and sudden release of stresses around the mine openings [32]. In addition, two prevailing explanations for undesired effects in the mining industry remain over exposure to gases (suffocation) and over exposure to coal dust [33]. Last but not least, underground mining is usually carried out in Pakistan with the room and pillar extraction method, which is the shabbiest and most dangerous method, and according to Nitish and Yardarshu, this mining technique was discarded worldwide [34]. It should be remembered, as far as the F-N Curve is concerned, that it is a useful way of comparing industries. Similar curves for entire industries and activities have been built and examples are included in Evans' book [36]. The FN-curves are a graphical display of information on 
the occurrence of fatal incidents in the system and the distribution of the number of fatalities in such accidents. They plot the $\mathrm{F}(\mathrm{N})$ frequency of no-more-fatality injuries, where $\mathrm{N}$ ranges from 1 to the maximum possible number of fatalities in the system. The lower the FN-curve on the FN- graph, the safer the structure it reflects since lower FN-curves are lower than higher curves in the likelihood of fatal accidents [37].



Figure2. presents the F-N Curve graph for the data set of fatal accident events across the Pakistani Mining industry for the period between 2017 and 2018

\section{CONCLUSiON}

There is a well-known understanding globally that the behaviour of industrial workers towards safety is impacted by their perception of risk, management, safety practices and regulations. In fully identifying the threats to human health, there are hereditary inconveniences. In other words, protection, not arithmetic, can be described as algebra (has variables). For example, there are a large number of human variables that affect safety and occupational injuries, such as age, race, gender, socio-economic status, education, awareness and awareness of both workers and employers, and work and environmental conditions. What is required is to balance all the risks against the benefits in order to guarantee a full safety margin. Among developed and developing countries, the overall cost-avail figure differs significantly.

As far as Pakistan's agriculture/forestry/fishery industry is concerned, the first step in minimizing occupational accidents is a ban on working for children under 18 years of age and older people, and this will be a game changer with television and radio campaigns. Second, there should be a national compulsory special education programme for the rural areas of Pakistan and for all four provinces. The efficacy of various measures has not been measured. This is important for further improvements in the design of farming tools, as most of them are hand tools. Weather alerts are important, particularly in the summer when the monsoons prevail and anti-draining projects and regulated changes in the course of the river in case of overflow.

The first rostrum in the manufacturing sector is the compulsory worker trainee. For all current and potential staff, the knowledge of acceptable clothing with uniforms, gloves, boots and helmets must be a stage for the trainee. It is something that workers must start not only by themselves but also to inspire their colleagues who do not discipline such an exhortation to get dressed with suitable clothes. The injuries can

be reduced by the trainee and the follow-up of relevant rules by the workers of these industries. From the perspective of undesirable lighting and unsuitable ventilation systems, their working environment has to do with hazardous chemicals or unsafe environments, as we have mentioned in our examples. Therefore, supervision of these persons (Governmental Authorities) and stringent fines for businesses that do not provide desirable working conditions would enhance the improvement of the hygiene and 
work climate. A high-risk occupational sector in the industry was found to be the building industry. The combination of many factors, such as the high-risk nature of construction work and limited knowledge and lack of understanding of trade risks among construction workers, explained this. It is clear that avoiding incidents before they occur is the most active way to strengthen the implementation of security. Security risk analysis is thus a vital basis on which safety management can be enhanced and risk evaluation, which forms an integral part of safety management systems, becomes an essential opus. Safety professionals must ensure on-site safety management to increase the security efficiency of the construction industry. Improving the understanding and knowledge of safety risks by safety practitioners would affect the efficiency and reliability of risk assessment.

The mining and quarrying business is also a high-risk occupational sector of the industry. Jobs are victims of workplace injuries in a conflict with safety laws due to no proper education, knowledge of safety and lack of training. Therefore, mine inspectors should specifically mandate businesses to comply with safety regulations. The amelioration would start from replacing the room \& pillar methods with safer methods such as underground, open surface, placer, and in-situ mining, due to the fact that the many accidents come from the old methods that are used and due to ground collapse, which implies lack of understanding of the geological conditions, and guarantee professionals with industrial expertise so that the errors are avoidable. In addition, the incidence of back injuries can only be reduced by adequate occupational subsistence and by educating workers in the use of heavy load lift techniques. In general, relative to other jobs, workers in all manufacturing sectors are the most vulnerable to hazards. In order to become aware of protection and loss of life, employees in the industrial sectors need to be aware. It should not be forgotten that safety looks like algebra (it has variables that alter each time and with different conditions) and not geometry that can come to the solution following axioms or theorems.

\section{REFERENCES}

[1] Ceylan H. “A new approach to occupational accidents: Technique of deviation from means” Energy Education Science and Technology Part B: Social and Educational Studies 2013; 5(2):819- 830

[2] International Labor Organization. "World day for safety and health at work 2009: facts on safety and health at work" [Internet]. 2009 Apr [cited 2017 Jun 17]. Available from: http://www.ilo.org/ wcmsp5/groups/public/@dgreports/@dcomm/documents/publication/wcms_10546.

[3] International Labor Organization. “Accurate data will help to save lives” [Internet]. 2017 Apr [cited 2017 Jun 17]. Available from: http://www.ilo.org/global/about-the-ilo/how-the-ilo- works/ilo-director-general/ statements-and-speeches/WCMS_551573/lang--en/index.htm

[4] Unsar AS, Sut N. “Occupational Accidents In The Energy Sector: Analysis of Occupational Accidents That Occurred In Thermal And Hydroelectric Centrals Between 2002 And 2010 In Turkey” ProcediaSocial and Behavioral Sciences 2015; 181:388-397

[5] Pakistan Economic survey 2019-20. Population, labour force and employment. Chapter 12.Available from:http://www.finance.gov.pk/survey/chapter_20/12_Population_Labour_Force_and_Employ ment.pdf.

[6] International Labour Standards Unit. “Occupational Safety\&Health: Legal Framework \& Statistical Trend Analysis (2010-2015)" [Internet]. 2016 Apr [cited 2017 Jun 18]. Available from: http://ophrd. gov.pk/hrd/userfiles1/file/OSH.pdf

[7] Pasha TS, Liesivuori J. “Country Profile on Occupational Safety and Health in Pakistan” Finnish Institute of Occupational Health, Centre for the Improvement of Working Conditions and Environment Lahore Pakistan; 2003

[8] Asia Monitor Resource Centre (AMRC). "National Workshop: Occupational Safety and Health (OSH) in Pakistan” 26-27 January 2013. Lahore (Pakistan); Hotel Ambassador; 2013 International Labour Organization. "Ratifications for Pakistan" [Internet]. 2016 [cited 2017 Jun 18] Available from:http://www.ilo.org/dyn/normlex/en/f?p=NORMLEXPUB:11200:0::NO::P11200_COUNTR Y_ID: 103166

[9] Riaz H. “Occupational, Health Safety and Environment in Textiles” [Internet]. 2010 Oct [cited 2017 Jun 18]. Available from: http://iepkarachi.org.pk/O\%20H\%20S\%20E\%20in\%20Textile---\%20Ms .\%20 Hafsa\% 20Riaz. pdf

[10] Baker SP, O'Neill B, Karpf RS. The injury fact book. Lexington, MA: D.C. Health and Company, 1984. 
Occupational Health and Safety Conditions from 2010 to 2018 in Different Major Industrial Sectors of Pakistan

[11] Cogbill TH, Busch Jr HM, GR, Stiers GR. Farm accidents in children. Pediatrics 1985; 76: $562-566$.

[12] Kumar A, Varghese M, Mohan D. "Equipment Related Injuries in Agriculture: An International Perspective” Injury Control and Safety Promotion (2000), 7: 3,175-186

[13] Sayeeda A. Sayed, Pedro Arcos González. Flood Disaster Profile of Pakistan: A Review. Science Journal of Public Health. Vol. 2, No. 3, 2014, pp. 144-149. doi: 10.11648/j.sjph.20140203.11

[14] Oxfam's Policy Paper. Ready or Not: Pakistan's resilience to disasters one year on from the floods. 2011. Available from: http://policy practice.oxfam.org.uk/publications/ready-or-not-pakistans- resilience-todisasters-one-year-on-from-the-floods-13868

[15] Khurram Chohan ${ }^{1 *}$, Sajid Rashid Ahmad ${ }^{1}$, Ziaul Islam ${ }^{1}$, Muhammad Adrees ${ }^{2}$, Riverine Flood Damage Assessment of Cultivated Lands along Chenab River Using GIS and Remotely Sensed Data: A Case Study of District Hafizabad, Punjab, Pakistan, Journal of Geographic Information System, 2015, 7, 506-526

[16] Khan MN, JanjuaMY. "Improvement in Fisher Health and Safety through Poverty Alleviation: A Case Study on the Indus Basin Fishing Communities in Pakistan" Second Conference on International Fishing Industry Safety and Health 2006; 91-102

[17] Munir A, AR Tahir and MS Sabir, 2003. Optimization of milling performance of sugar plant by usinglinear programming technique. PakistanJournal Agricultural Science, 40(1-2): 87-92.

[18] Anjum Munir ${ }^{1}$, Muhammad Adeel Ashraf ${ }^{1}$, Abdul Nasir ${ }^{2}$, Oliver Hensel ${ }^{3}$ and Muhammad Iqbal”" Ergonomics and Occupational Health in Sugar Industry of Pakistan 'Pakistan journal of life social Sciences (2012), 10(1): 74-79

[19] Rana, I.M. 2005. Work places in industries. The daily Dawn. p.18.

[20] Ahasan, M.R. and T. Partanen. 2001. Occupational health and safety in the least developed countries-a simple case of neglect. J. Epidemiology. 11(2): 74-80.

[21] Nazia Malik ${ }^{1}$, Ashfaq Ahmed Maan1, Tariq Sultan Pasha ${ }^{2}$, Saira Akhtar1 and Tanvir Ali3, "ROLE OF HAZARD CONTROL MEASURES IN OCCUPATIONAL HEALTH AND SAFETY IN THE TEXTILE INDUSTRY OF PAKISTAN”,Pak. J. Agri. Sci., Vol. 47(1), 72-76; 2010

[22] Niza, C., Silva, S., Lima, M.L., 2008. Occupational accident experience association with workers' accident explanation and definition. Safety Science 46 (4), 959-971.

[23] Liao, C.W., Perng, Y.H., 2008. Data mining for occupational injuries in the Taiwan construction industry. Safety Science 46 (7), 1091-1102.

[24] Ivan W.H. Fung,Vivian W.Y. Tam*, Tommy Y. Lo, Lori L.H. Lu,'Developing a Risk Assessment Model for construction safety”,International Journal of Project Management 28 (2010) 593-600

[25] Sherif Mohamed and Tauha Ali, "Safety Behaviour in the Construction Industry in Pakistan", 4TH Triennial International Conference, Rethinking and Revitalizing Construction, Safety, Health, Environment and Quality,Port Elizabeth - South Africa,17-20 May 2005,ISBN 0-620 -33919- 5,pp. 64-75

[26] Mining-Technology.com,http://www.mining-technology.com/features/feature-world-worst-coal-miningdisasters-china/

[27] S.Rosen and B.R James, 2005 "Land Degradation due to Coal extraction" American journal of environmental sciences Vol. 3-4(5); 45-56

[28] B.Sernia and Jang, M, Hwang 2007 "Coal mining dangers" International journal of occupational health, Vol. 1-5(9): 3-18.

[29] K. J. Jadoon and J. S. Edwards, "Risk Evaluation of Lost Time Injuries in the Coal Mining Industry in Pakistan”, Journal of Engineering and Applied Science, Volume 18,No 1,January-June 1999

[30] K. J. Jadoon, J. S. Edwards and T. N. Khan, "Groundfall Accidents the Main Concern for the Coal Mining Industry in Pakistan", Journal of Engineering and Applied Science, Volume 13, No 2, July-December 1994

[31] Salahuddin Azad, Maqsood Ahmad Khan and Zarmina Akbar,"DISASTER MANAGEMENT IN COAL MINE INDUSTRY OF BALOCHISTAN", European Scientific Journal October 2015/SPECIAL/ edition Vol.1 ISSN: 1857 - 7881 (Print) e - ISSN 1857- 7431

[32] J.S Nitish and V.P Yardarshu 2008" Impacts of mining industries in Jharkhand" Indian journal of occupational Medicines Vol. 6-3(31): 36-43. 
Occupational Health and Safety Conditions from 2010 to 2018 in Different Major Industrial Sectors of Pakistan

[33] http://www.industria-union.org/sites/default/files/uploads/documents/2016/Pakistan/mining_accidents_in_ pakis tan_2010-2016.pdf

[34] A. W. Evans. RR073-Transport fatal accidents and FN-curves: 1967-2001. Health and Safety Executive. 2003. URL www.hse.gov.uk/research/rrpdf/rr073.pdf.

[35] Transport fatal accidents and FN-curves: 1967-2001, University College London for the Health and Safety Executive 2003.

Citation: Satesh Kumar Devrajani, (2021). “Occupational Health and Safety Conditions from 2010 to 2018 in Different Major Industrial Sectors of Pakistan". International Journal of Innovative Research in Electronics and Communications (IJIREC), 8(1), pp.1-8. DOI: http://dx.doi.org/10.20431/2349-4050. 0801001

Copyright: () 2021 Authors. This is an open-access article distributed under the terms of the Creative Commons Attribution License, which permits unrestricted use, distribution, and reproduction in any medium, provided the original author and source are credited. 